\title{
Fluid, electrolytes and nutrition
}

\author{
Simon Allison
}

ABSTRACT - Nutrition and fluid and electrolyte balance are inextricably linked through ingestion, digestion, absorption and intermediary metabolism. Studies are described showing that man's physiological capacity to excrete excess salt and water is limited under normal conditions; it is further reduced by starvation and injury, so that patients are easily overloaded, resulting in increased complications of illness and surgery. Return of gastrointestinal function postoperatively is delayed by moderate saline overload. IIIness not only influences external fluid and electrolyte balance but also internal balance between the extracellular and intracellular spaces and between the intravascular and extravascular components of the extracellular space. The mechanisms and management of these changes are discussed. The importance of fluid and electrolyte balance in nutritional support is emphasised indeed, the benefits of nutrition may be negated by electrolyte imbalance. The relationships between serum albumin concentration, illness, nutrition and fluid balance are discussed and the limited role of albumin infusions described. Surveys among doctors have revealed a poor knowledge of fluid and electrolyte balance. Measures are needed to improve training.

KEY WORDS: albumin, fluid overload, knowledge and training, metabolism, nutrition, salt and water balance

Following emergence from the sea, organisms developed their own internal sea (milieu intérieur) in which their cells could bathe in an isosmotic environment of constant temperature and across which nutrients and gases could pass to and fro between the cell and the circulation. The chemical stability of this internal environment depends, not only on the ingestion of water and salt during feeding and the physiological control of losses by the kidney, skin and gut, but also upon metabolism and the internal mechanisms which maintain equilibrium between each of the body fluid compartments. Terrestrial evolution has taken place in an environment with wide fluctuations in the availability of water and a diet high in potassium but low in sodium. Only recently has this situation been challenged by excess sodium chloride in the diet or in crystalloid infusions used in hospital. Although, therefore, our physiology is well adapted by evolutionary pressures to manage lack or excess of water or salt deficit, it copes poorly with salt excess in either health or disease. We are also relatively intolerant of deficit or excess of extracellular fluid (ECF) volume, with as little as $10 \%$ deviation either way producing significant symptoms and functional change.

\section{Body fluid compartments in health and disease}

Fluid and electrolyte balance in the clinical setting must be considered not only in terms of external balance between the body and its environment but also in terms of internal balance between the body fluid compartments, since both may be deranged by disease.

This article is

based on the

Oliver-Sharpey

Lecture given at

the Royal College

of Physicians on

11 December

2002 by Simon

Allison MD FRCP,

Consultant

Physician and

Professor of

Clinical Nutrition,

Queen's Medical

Centre, University

Hospital,

Nottingham

Clin Med

2004:4:573-8

\section{Key Points}

In clinical practice, account should be taken of external balance and of internal fluxes and balances between body fluid compartments. Both external and internal balances are inextricably linked to nutrition and metabolism and are disturbed in disease

The capacity of healthy subjects to respond physiologically to water excess or lack of water or salt has been developed through evolution. Lack of exposure to salt excess may explain our relatively underdeveloped capacity to respond to it. Salt excretion seems to depend on the permissive effect of reduced secretion of renin, angiotensin and aldosterone. Natriuretic peptide is responsive to acute intravascular volume increase but not to an excess intravenous saline load per se. $\mathrm{Cl}^{\mathrm{G}}$ may be as important in this respect as $\mathrm{Na}+$ excretion. Excess saline, with its high ratio of $\mathrm{Cl}^{\mathrm{G}}$ to $\mathrm{Na}+$ compared with plasma, may cause hyperchloraemic acidosis which may exacerbate protein catabolism

Retention of salt and water is exacerbated by starvation and response to injury. Some interstitial salt and water load may be an inevitable consequence of resuscitation from shock, but excess saline infusion for daily maintenance of urine output should not be continued. Provided that plasma and extracellular fluid volumes are normal, this is best achieved by water or $5 \%$ dextrose, with only that amount of sodium which replaces losses

Deviations of 2-3 litres in fluid balance from normal produce significant symptoms as well as impairment of mental and physical function. Saline excess impairs the return of gastrointestinal function after surgery and increases complications

Knowledge and practice among many young clinicians is poor in the fields of nutrition and of fluid and electrolyte balance; both need improvement 
Table 1. Changes in intracellular metabolites and electrolytes in critically ill patients, obtained from muscle biopsies. ${ }^{2}$

\begin{tabular}{lcccc}
\hline & $\begin{array}{c}\text { Glycogen } \\
(\mu \mathrm{mol} / 100 \mu \mathrm{mol} \\
\text { creatine })\end{array}$ & $\begin{array}{c}\text { Sodium } \\
(\mu \mathrm{mol} / 100 \mu \mathrm{mol} \\
\text { creatine })\end{array}$ & $\begin{array}{c}\text { Potassium } \\
(\mu \mathrm{mol} / 100 \mu \mathrm{mol} \\
\text { creatine })\end{array}$ & $\begin{array}{c}\text { Total creatine } \\
(\mu \mathrm{mol} / \mathrm{g} \\
\text { dry weight })\end{array}$ \\
\hline $\begin{array}{c}\text { Patient: } \\
\text { median }\end{array}$ & 164 & 201 & & 94.6 \\
range & $78-407$ & $125-507$ & 274 & $43.3-121$ \\
Normal range & $151-383$ & $40-132$ & $319-415$ & $108-159$
\end{tabular}

\section{Extracellular fluid versus intracellular fluid: the metabolic tide of the cell}

Total body water is approximately $60 \%$ of body weight in an average adult. In contrast to muscle which is $75 \%$ water, adipose tissue is only $5 \%$ so water forms a lower proportion of the body mass in obese subjects. The body water is divided into the intracellular fluid (ICF) (40\% of body weight) and the ECF (20\% of body weight), separated by the cell membrane whose sodium pump ensures that the sodium concentration is less than $8 \mathrm{mmol} / \mathrm{l}$ in the ICF and $140 \mathrm{mmol} / \mathrm{l}$ in the ECF. The large molecules of protein and glycogen have negative charges which hold potassium within the cell $(150 \mathrm{mmol} / \mathrm{l}$ in contrast to $4-5 \mathrm{mmol} / \mathrm{l}$ in the ECF).

This relationship breaks down during critical illness: protein and glycogen are catabolised to amino acids and glucose, which then leave the cell accompanied by potassium. At the same time, sodium is pumped less efficiently and accumulates within the cell (Table 1).1,2 With recovery from illness or starvation, glycogen and protein anabolism is accompanied by cellular uptake of potassium and phosphate whose extracellular concentrations fall. Glycogen formation also obliges the cellular uptake of water.

There is therefore a metabolic tide which ebbs to and fro across the cell membrane between the sea of ECF and the ICF, as feeding alternates with fasting or the catabolic effects of illness give way to the anabolism of recovery and convalescence. The use of high-dose insulin, with glucose and potassium to reduce protein catabolism in burned and other catabolic patients, was first described in the 1970 s. $^{3-5}$ In contrast to the sodium- and water-retaining effects of carbohydrate in starvation ${ }^{6}$ and of insulin in normal, obese and diabetic patients, ${ }^{7-9}$ in the salt-overloaded patient after injury ${ }^{4}$ or with heart failure ${ }^{10}$ high-dose insulin induces a salt and water diuresis, possibly due to enhancement by insulin and glucose of cellular sodium pumping with reversal of the 'sick cell syndrome'.

\section{Plasma versus interstitial fluid}

The ECF is itself separated by the capillary membrane into the intravascular plasma and extravascular or interstitial fluid bathing the cells. The integrity of the intravascular volume depends on the:

- concentrations of plasma proteins (oncotic pressure)
- relative impermeability of the pores in the capillary membrane to large molecules such as albumin, and

- hydrostatic pressure within the capillary in relation to that outside it.

Even in normal subjects, however, there is a continuous flux between the two compartments such that the intravascular albumin leaks out of the circulation into the interstitial space at a rate of $5 \%$ per hour and is returned to the circulation via the lymphatic system. This represents the average of the whole body, for the balance of Starling forces varies considerably between different tissues. Although the pulmonary and hepatic microcirculations have a lower hydrostatic pressure, their permeability to proteins is much greater than in other tissues such as muscle, ${ }^{11}$ so that transudate is more likely to develop in the splanchnic and pulmonary tissues than elsewhere. There is also more albumin in the interstitial than in the intravascular space $(170 \mathrm{~g}$ vs $140 \mathrm{~g}$ ) and the flux between them is 10 times the rate of albumin synthesis. ${ }^{12}$

\section{Hypoalbuminaemia}

The cytokine response to injury increases the permeability of the capillary membrane to proteins, causing the typical swelling and inflammation at the site of injury and a more generalised increase in capillary permeability throughout the body. Albumin is thereby redistributed from the intravascular to the interstitial space, contributing to the fall in serum albumin concentration during illness. The albumin escape rate increases from $5 \%$ to $14 \%$ per hour after uncomplicated major surgery, returning to normal over 10 days. ${ }^{13}$ Albumin escape also correlates positively with C-reactive protein levels (reflecting inflammation) and inversely with the serum albumin concentration (reflecting redistribution). Hypoalbuminaemia is also caused or exacerbated by dilution from infused crystalloids.

Management of hypoalbuminaemia. The management of hypoalbuminaemia ${ }^{14,15}$ is that of its underlying cause, that is:

- reducing inflammation

- preventing or reversing dilution

- treating liver disease and, in some cases,

- improving nutrition. ${ }^{16}$

There is little or no evidence of benefit from the use of albumin to treat hypoalbuminaemia per se or in acute hypovolaemic 
or septic shock, except possibly in meningococcal septicaemia in children and subacute peritonitis in liver disease. ${ }^{17}$

In the postacute phase, however, some 7-10 days after the initial insult, the situation may be different. At this stage, patients may be oedematous from excess fluid administration, as well as hypoalbuminaemic due to previous albumin redistribution and dilution, and to serous losses from wounds or inflamed surfaces. Management depends on the state of the intravascular volume, whether high, low or normal. If, on examination with the patient at $45^{\circ}$, the jugular venous pressure is elevated, the intravascular volume is probably expanded and loop diuretics may be appropriate. If, on the other hand, the jugular vein is not even distended as the patient is lowered to the horizontal position (or the measured central venous pressure is low) and other features suggest hypovolaemia, such as tachycardia, hypotension and oliguria, a low intravascular volume may be inferred. Albumin seems justified in this postacute phase, for several reasons:

- it is illogical to use salt-containing crystalloids or colloids in the presence of oedema

- oedema cannot be cleared in the presence of a low plasma volume and renal plasma flow

- the transcapillary escape rate of albumin has usually returned to normal by this time.

To correct plasma volume, restore sensitivity to diuretics and induce a diuresis, it is usually sufficient to give two to four $100 \mathrm{ml}$ units of $20 \%$ salt-poor albumin over 48 hours. Once volume is corrected, it is rare for further infusions to be needed. If, however, intravascular volume appears to be normal, with good tissue perfusion and urine flow, the patient will probably clear their excess fluid load without treatment, provided that no further salt-containing fluids are administered.

\section{Flux through the gastrointestinal tract}

The flux of water and salt through the kidney is well known, with 180 litres of ECF being filtered and all but 1-2 litres and 50-100 mmol of sodium reabsorbed. Another important flux occurs through the gut (Fig 1) with 8 litres of fluid, mainly secretions, passing daily through the small bowel with a sodium concentration of $110-120 \mathrm{mmol} / \mathrm{l}$. By the time bowel contents reach the ileocaecal valve, all but $1,500 \mathrm{ml}$ have been absorbed and all except $150 \mathrm{ml}$ of the rest absorbed in the colon. This flux is closely linked to nutrition, since salt and water absorption in the jejunum is linked to carbohydrate digestion and absorption (the basis for rehydration solutions) and that in the large bowel to absorption of short-chain fatty acids derived from bacterial fermentation of soluble fibre. Bowling ${ }^{18}$ has shown that enteral feeding by duodenal tube excites salt and water secretion into the lumen of the ascending colon but, if short-chain fatty acids are infused simultaneously into the caecum, there is net colonic absorption of salt and water.

In addition to having nutritional consequences, any breakdown in the integrity or absorptive function of the gastrointestinal (GI) tract can result in pooling or loss of large volumes of ECF. A knowledge of the likely electrolyte concentration of lost fluid (Table 2) is invaluable in guiding appropriate replacement. In prescribing parenteral nutrition for such patients, it is as important to consider the precise requirements for fluid and electrolytes as those for energy, protein and micronutrients, water balance being then monitored by daily weighing. Assuming normal activity of the sodium pump and that the change in water balance is known, sodium balance may be inferred from the change in plasma sodium concentration. Patients with a large fistula output and GI failure can be managed indefinitely using these principles, without the necessity for frequent measurement of the electrolyte content of fistula fluid.

\section{Studies in normal subjects}

To improve our understanding of the response to crystalloid infusion in patients, we conducted a series of studies on the effect of such infusions in normal subjects. In the first study, ${ }^{19}$ weekly comparisons were made of the effect of giving 2 litres of $5 \%$ dextrose or $0.9 \%$ saline over one hour, taking measurements over the subsequent five hours. Both solutions caused weight gain of $2 \mathrm{~kg}$ but, whereas the water from 5\% dextrose was excreted rapidly, $60 \%$ of the salt and water from the saline was retained after six hours with persisting dilution of the haematocrit and albumin. This illustrates the efficiency with which a 
Table 2. Electrolyte content of gastrointestinal fluids.

\begin{tabular}{lcccc}
\hline & $\begin{array}{c}\mathrm{Na}+ \\
(\mathbf{m m o l} / \mathrm{l})\end{array}$ & $\begin{array}{c}\mathrm{K}+ \\
(\mathbf{m m o l} / \mathrm{l})\end{array}$ & $\begin{array}{c}\mathrm{CIG} \\
(\mathbf{m m o l} / \mathrm{l})\end{array}$ & $\begin{array}{c}\mathrm{HCO}_{3 \mathrm{G}} \\
(\mathbf{m m o l} / \mathrm{l})\end{array}$ \\
\hline Saliva & 10 & 26 & 10 & 30 \\
Gastric: & & & & \\
$\quad\left({ }_{8} \mathrm{HCl}_{\mathrm{G}}\right)$ & 20 & 10 & 120 & 0 \\
$\left.\quad{ }_{9} \mathrm{HCl}_{\mathrm{G}}\right)$ & 80 & 15 & 90 & 0 \\
Jejunum & 110 & 5 & 105 & 30 \\
Distal ileum & 88 & 8 & 45 & 30 \\
Colon & 60 & 30 & 40 & 0 \\
Bile & 145 & 5 & 100 & 35 \\
Pancreas & 140 & 5 & 75 & 115
\end{tabular}

water load is excreted, in contrast to the slow clearance of saline excess, even in healthy subjects.

Hormone responses to fluid infusion were then measured using one-litre volumes given over one hour. ${ }^{20}$ Vasopressin and renin angiotensin aldosterone secretion (RAAS) fell after both saline and dextrose, although the fall in vasopressin was more marked after dextrose and in RAAS after saline. Levels of natriuretic peptide (ANP) rose identically during infusion of either solution, but returned to baseline when the infusion was completed despite the residual positive sodium balance after saline. This suggests that ANP is sensitive to intravascular volume rather than positive sodium balance per se, the clearance of which seems to depend on the slow passive effect of reduced RAAS activity.

Sodium ion may not be the only problem. So-called 'normal' or $0.9 \%$ saline is in fact quite unphysiological. The ratio of chloride ions $\left(\mathrm{Cl}^{\mathrm{G}}\right)$ to sodium ions $\left(\mathrm{Na}^{+}\right)$in plasma is $1: 1.38$,

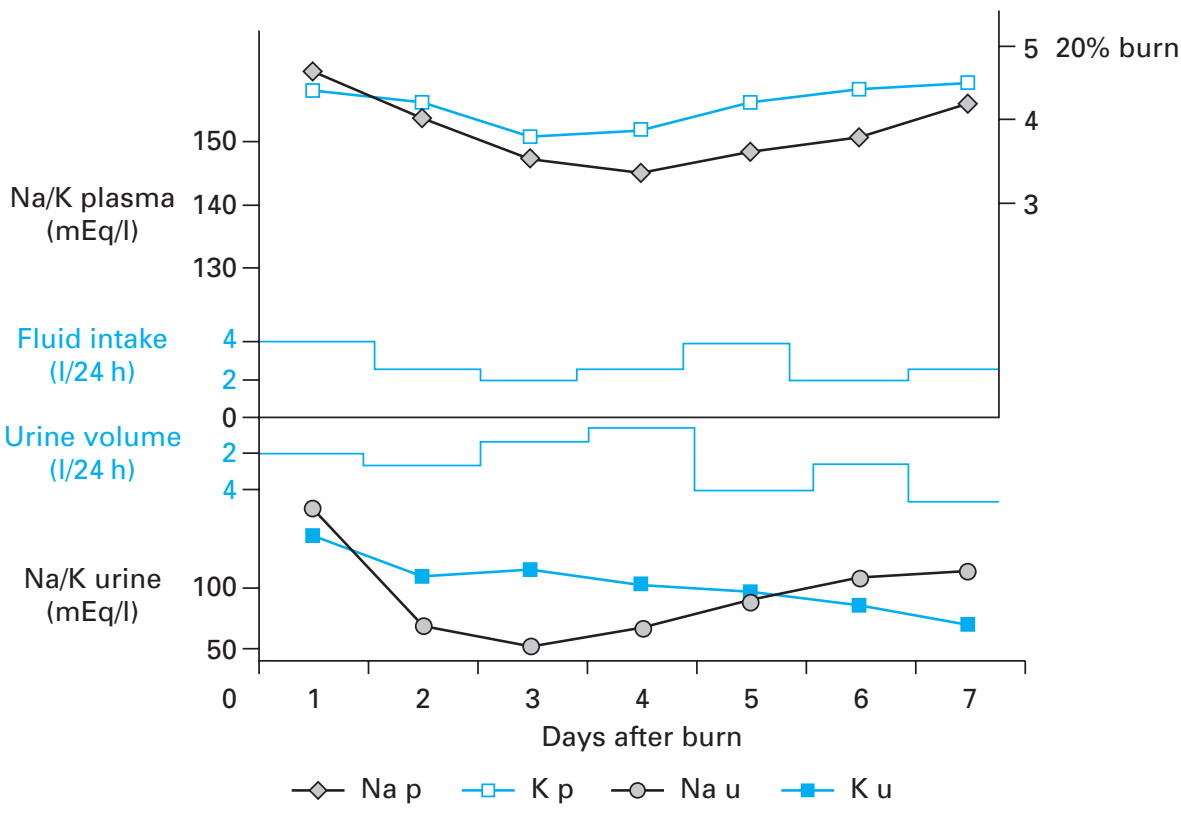

Fig 2. Change in urinary and plasma electrolytes in the first week following a moderate $(20 \%)$ burn, showing the 'sodium retention' and 'sodium diuresis' phases of injury 4 ( $p=$ plasma; $u=$ urinary). whereas in saline it is 1:1, resulting in a rise in plasma chloride and even hyperchloraemic acidosis after saline infusions. ${ }^{21}$ This causes not only an adverse effect on nitrogen balance, because of the kidney's need for glutamine to form ammonia to excrete hydrogen ion, but also renal vasoconstriction and reduced glomerular filtration rate. ${ }^{22}$

In the 1920s and 1930s, Ringer and Krebs tried to devise a more physiological solution than saline (Ringer lactate). The modern clinical version of this, Hartmann's solution, has a more physiological ratio of $\mathrm{Cl}^{\mathrm{G}}$ to $\mathrm{Na}^{+}$of 1:1.1, the anion gap being substituted by lactate. The effects of one-litre infusions of $0.9 \%$ saline and Hartmann's solution were also compared. ${ }^{23}$ Despite the lower sodium content of Hartmann's, sodium and water excretion over the four hours postinfusion was greater than after $0.9 \%$ saline, confirming that $\mathrm{Cl}^{\mathrm{G}}$ may be an important factor in delaying excretion of a salt load.

\section{Effects of starvation and injury on water and electrolyte balance}

Starvation and injury not only affect the distribution of fluid and electrolytes between the body fluid compartments but also the external balance between the body and its environment. Normal volunteers subjected to semistarvation for 24 weeks lost $23 \%$ of their body weight. ${ }^{24} \mathrm{ECF}$ rose as a percentage of body weight; this may give rise to famine or refeeding oedema, depending upon salt and water intake.

The decreased salt tolerance of patients in response to trauma, surgery or acute illness has been known since the beginning of the 20th century. Following surgery, sodium, chloride and water are retained and potassium lost. The terms 'sodium retention' phase and 'sodium diuresis' phase characterise, respectively, the response first to injury and then to convalescence when the capacity to excrete excess salt and water returns. Figure 2 illustrates the changes in sodium, potassium and water excretion with decreased sodium and water and increased potassium excretion during the first few days after a $20 \%$ burn injury ${ }^{4}$ despite large infusions of salt-containing resuscitation fluids. The excretion of potassium reflects not only a response to mineralocorticoid but also its release from cells as protein and glycogen are catabolised. This was only a moderate injury so the 'sodium retention' phase was followed by the 'sodium diuresis' phase after only a few days. In the presence of more severe injury or complications, sodium diuresis is delayed so that there is increasing cumulative balance (Fig 3) and oedema if excessive amounts of salt continue to be administered, with adverse consequences (see below).

Free water clearance is also impaired 
by surgery, as shown in a series of postoperative patients receiving fluid in the form of three litres per day of $0.18 \%$ saline in $4 \%$ dextrose. Even five days postoperatively, plasma osmolality was still depressed with an inappropriately high urine osmolality (Table 3 ). ${ }^{25}$ Excess administration of such hypotonic fluids may therefore cause dangerous hyponatraemia.

\section{Clinical observations in oedematous patients}

The patients referred for nutritional support were audited, ${ }^{26}$ divided into those with chronic nutritional depletion and those with complications of trauma or surgery, nearly all of whom were oedematous at the time of referral (usually 5-14 days after initial injury). In the latter group, the first task was to restore fluid and electrolyte balance and to clear oedema by stopping salt intake and using diuretics. Among those with reduced plasma volume, 20\% salt-poor albumin was first infused as described above. The mean fall in weight between referral and plateau 7-10 days later was $10 \mathrm{~kg}$ as the oedema resolved. Serum albumin rose by $1 \mathrm{~g} /$ litre for every $1 \mathrm{~kg}$ of fluid lost, reflecting a reversal of the diluting effect of crystalloid. Clearance of oedema also appeared to be associated with a return of GI function, allowing nutritional support via the oral or enteral rather than parenteral route. In some cases, the price for adequate initial resuscitation and restoration of intravascular volume in shock may be interstitial overload. However, there is often a failure to distinguish between the requirements for initial replacement and those for subsequent maintenance, resulting in ever increasing overload and its complications. ${ }^{27}$ Fluid balance can usually be maintained with modest volumes of water or $5 \%$ dextrose, with less than $70 \mathrm{mmol}$ of sodium daily to ensure an adequate urine output, provided that the plasma and ECF volumes are normal, renal perfusion is adequate and there are no abnormal losses.

Table 3. Effects of hypotonic crystalloids (3 litres/day) postoperatively showing the fall in plasma osmolality and inability to dilute the urine and increase free water clearance appropriately. ${ }^{25}$

\begin{tabular}{lcccccc}
\hline & \multicolumn{6}{c}{$\begin{array}{c}\text { Osmolality (mosmol/kg) } \\
\text { (days after operation) }\end{array}$} \\
\cline { 2 - 7 } Fluid & 0 & 1 & 2 & 3 & 4 & 5 \\
\hline Plasma & 282 & 279 & 273 & 273 & 270 & 270 \\
Urine & 579 & 696 & 610 & 358 & 489 & 611
\end{tabular}

\section{Effects of salt and water overload on gastrointestinal function}

In 1937, Mecray et al ${ }^{28}$ observed a delayed return of gastroenterostomy function postoperatively in two oedematous hypoalbuminaemic patients. In dogs infused with saline after removing plasma, gastric emptying was prolonged tenfold. We studied this phenomenon in a model of patients undergoing uncomplicated hemicolectomy for cancer, ${ }^{29}$ comparing two intravenous regimens:

- 3 litres of water and at least $150 \mathrm{mmol}$ of salt, and

- restriction to 2 litres of water and $70 \mathrm{mmol}$ of salt daily.

The latter regimen maintained zero balance whereas the former caused a $3 \mathrm{~kg}$ positive fluid balance and dilution of haematocrit and serum albumin. On the fourth day postoperatively, the restricted group had normal gastric emptying and were eating, whereas all those receiving the first regimen had prolonged gastric emptying, three were still vomiting and none was eating normally. There were fewer complications in the restricted group, bowel function returned two days earlier and they could be discharged three days earlier.

These studies emphasise the importance of accurate fluid and electrolyte balance and the intolerance of patients to quite small deviations from normal.

\section{Knowledge and training}

A survey of practice and knowledge of fluid and electrolytes among 200 junior doctors ${ }^{30}$ and 700 consultant surgeons ${ }^{31}$ found that:

- intravenous fluid prescriptions are usually left to the most junior member of the team 
- junior doctors' confidence in their knowledge was shown to be misplaced: for example, $75 \%$ did not know the sodium content of $0.9 \%$ saline

- education and training at both undergraduate and postgraduate level are poor and require improvement.

\section{References}

1 Flear CT, Singh CM. Hyponatraemia and sick cells. Review. Br J Anaesth 1973;45:976-94.

2 Campbell IT, Green CJ, Jackson MJ. Muscle glycogen and electrolyte concentrations in multiple organ failure. Proc Nutr Soc 1998;57:111A.

3 Hinton P, Allison SP, Littlejohn S, Lloyd J. Insulin and glucose to reduce catabolic response to injury in burned patients. Lancet 1971;i:767-9.

4 Hinton P, Allison SP, Littlejohn S, Lloyd J. Electrolyte changes in burn injury and effect of treatment. Lancet 1973;i:218-21.

5 Woolfson AM, Heatley RV, Allison SP. Insulin to inhibit protein catabolism after injury. N Engl J Med 1979;300:14-17.

6 Franch G, Guirao X, Garcia-Domingo M, Gil MJ et al. The influence of calorie source on water and sodium balances during intravenous refeeding of malnourished rabbits. Clin Nutr 1992;11:59-61.

7 Norgaard K, Jensen T, Skøtt P, Thorsteinsson B et al. Effects of insulin on renal haemodynamics and sodium handling in normal subjects. Scand J Clin Lab Invest 1991;51:367-76.

8 Finta KM, Rocchini AP, Moorehead C, Key J, Katch V. Urine sodium excretion in response to an oral glucose tolerance test in obese and nonobese adolescents. Pediatrics 1992;90:442-6.

9 Gans RO, Bilo HJ, Nauta JJ, Heine RJ, Donker AJ. Acute hyperinsulinaemia induces sodium retention and a blood pressure decline in diabetes mellitus. Hypertension 1992;20:199-209.

10 Allison SP, Morley CJ, Burns-Cox CJ. Insulin, glucose, and potassium in the treatment of congestive heart failure. BMJ 1972;3:675-8.

11 Rose BD, Post TW. Clinical Physiology of Acid Base and Electrolyte Disorders, 5th edn. New York: McGraw-Hill, 2001.

12 Fleck A. Plasma proteins as nutritional indicators in the perioperative period. In: Allison SP, Kinney JM (eds). Perioperative Nutrition. Br J Clin Pract 1988;43(Suppl 63):20-4.

13 Anderson J, Lawes S, Lobo D, Rowlands B, Allison S. Sequential changes in serum albumin c-reactive protein and transcapillary escape rate of albumin in patients undergoing major abdominal surgery. Clin Nutr 2002;21(Suppl 1):29.

14 Allison SP, Lobo DN. Debate: Albumin administration should not be avoided. Review. Crit Care 2000;4:147-50.

15 Allison SP, Lobo DN, Stanga Z. The treatment of hypoalbuminaemia. Review. Clin Nutr 2001;20:275-9.

16 Bastow MD, Rawlings J, Allison SP. Benefits of supplementary tube feeding after fractured neck of femur: a randomised controlled trial. BMJ (Clin Res Ed) 1983;287:1589-92.

17 Sort P, Navasa M, Arroyo V, Aldeguer X et al. Effect of intravenous albumin on renal impairment and mortality in patients with cirrhosis and spontaneous bacterial peritonitis. N Engl J Med 1999;341:403-9.

18 Bowling TE, Raimundo AH, Grimble GK, Silk DB. Reversal by short-chain fatty acids of colonic fluid secretion induced by enteral feeding. Lancet 1993;342:1266-8.

19 Lobo DN, Stanga Z, Simpson JA, Anderson JA et al. Dilution and redistribution effects of rapid 2-litre infusions of $0.9 \%(\mathrm{w} / \mathrm{v})$ saline and $5 \%$ $(\mathrm{w} / \mathrm{v})$ dextrose on haematological parameters and serum biochemistry in normal subjects: a double-blind crossover study. Clin Sci (Lond) 2001;101:173-9.

20 Lobo DN, Myhill DJ, Stanga Z, Broughton-Pipkin F, Allison SP. The effect of volume loading with 1 litre intravenous infusions of $0.9 \%$ saline and 5\% dextrose on the renin angiotensin system (RAS) and volume controlling hormones: a randomised double crossover study. Clin Nutr 2002;21(Supp 1):9-10.

21 Ho AM, Karmakar MK, Contardi LH, Ng SS, Hewson JR. Excessive use of normal saline in managing traumatized patients in shock: a preventable contributor to acidosis. Review. J Trauma 2001;51:173-7.

22 Wilcox CS. Regulation of renal blood flow by plasma chloride. J Clin Invest 1983;71:726-35.

23 Reid F, Lobo DN, Williams RN, Rowlands BJ, Allison SP. (Ab)normal saline and physiological Hartmann's solution: a randomized doubleblind crossover study. Clin Sci (Lond) 2003;104:17-24.

24 Keys A, Brozek J, Henschel A, Mickelsen O, Taylor HF. The Biology of Human Starvation. Minneapolis: University of Minnesota Press, 1950.

25 Allison SP. Metabolic aspects of intensive care. Br J Hosp Med 1974; 11:860-71.

26 Lobo DN, Bjarnason K, Field J, Rowlands BJ, Allison SP. Changes in weight, fluid balance and serum albumin in patients referred for nutritional support. Clin Nutr 1999;18:197-201.

27 Holte K, Sharrock NE, Kehlet H. Pathophysiology and clinical implications of perioperative fluid excess. Review. Br J Anaesth 2002;89:622-32.

28 Mecray PM, Barden RP, Ravdin IS. Nutritional edema: its effect on the gastric emptying time before and after gastric operations. 1937. Nutrition 1990;6:278-89.

29 Lobo DN, Bostock KA, Neal KR, Perkins AC et al. Effect of salt and water balance on recovery of gastrointestinal function after elective colonic resection: a randomised controlled trial. Lancet 2002;359: $1812-8$.

30 Lobo DN, Dube MG, Neal KR, Simpson J et al. Problems with solutions: drowning in the brine of an inadequate knowledge base. Clin Nutr 2001;20:125-30.

31 Lobo DN, Dube MG, Neal KR, Allison SP, Rowlands BJ. Peri-operative fluid and electrolyte management: a survey of consultant surgeons in the UK. Ann R Coll Surg Engl 2002;84:156-60. 